\title{
Perawatan Electro Motor Oil Max Pump pada Mesin Induk KM Dharma Kartika IX
}

\author{
Andi Hendrawan ${ }^{1}$, Leonardus Heru Pratomo ${ }^{2}$, Siswadi $^{3}$ \\ ${ }^{1}$ Akademi Maritim Nusantara Cilacap \\ ${ }^{3}$ UNIKA Sugijopranoto \\ ${ }^{3}$ Universitas Maritim AMNI \\ andi_hendrawan@amn.ac.id
}

Diterima 20 September 2021, direvisi 29 September 2021, diterbitkan 06 Oktober 2021

\begin{abstract}
Abstrak
Masalah yang timbul pada elektro motor mesin adalah kerusakan mekanis yang dapat diakibatkan oleh banyak hal seperti kerusakan mekanis, arus lebih, low tahanan isolasi yang rendah dan kurang pelumasan, getaran berlebih serta tidak imbang, misalignment, proses penuaan alami dan faktor karena pola operasi motor induksi, kerusakan yang terjadi pada motor induksi. Data dikumpulkan melalui Field Research, peninjauan langsung pada objek yang diteliti. Data dikumpulkan melalui Observasi (Metode Secara Langsung) peneliti melakukan pengamatan langsung mengenai objek yang diteliti di kapal KM. DHARMA KARTIKA IX. Harus dilakukan perawatan komponen electro motor yaitu dengan memeriksa komponen electro motor beserta panelnya.
\end{abstract}

Kata kunci : Electro motor oil pump, motor induksi

\begin{abstract}
Problems that arise in the engine electro motor is mechanical damage that can be caused by many things such as mechanical damage, more current, low resistance low insulation and less lubrication, excess vibration and not draw, misalignment, natural aging process and factors due to the operating pattern of the induction motor, damage that occurs in the induction motor. Data is collected through Field Research, a direct review of the objects studied. Data collected through Observation (Direct Method) researchers make direct observations about objects studied on the SHIP KM. DHARMA KARTIKA IX. Must be done maintenance of electro motor components that is by checking the electro motor components and panels.
\end{abstract}

Keywords: Electro motor oil pump, induction motor

\section{Pendahuluan}

Perawatan sangat penting karena akan membuat komponen mesin[1] menjadi awet dan bisa merupakan deteksi dini pada kerusakan komponen mesin. Perawatan meruapak hasil yang wajib dalam setiap kegiatan di Atas Kapal. Setiap saat diadakan ngecekan agar mesin dapat berkerja dengan baik dan aman sehingga tercapai keselamatan.

Electromotor dipergunakan pada bidang industri kertas, ladang minyak pembangkit tenaga listrik dan pabrik. Pada umumnya menggunakan penggerak pompa, conveyor, pembangkit tenaga listrik, dan lain lan. Mesin listrik yang banyak dipergunkan adalh motor induksi paling dikarenakan kokoh, kuat mudah dalam merawat, dan efisiensi daya cukup tinggi. Permasalahan yang terjadi pada setiap electro motor kerusakan mekanis yang diakibatkan oleh mechanical failure (kerusakan mekanis), low insulation resistance (tahanan isolasi yang rendah) termasuk karena kurang pelumasan over-current (arus lebih), getaran berlebihan dan 
tidak imbang, atau karena misalignment, proses penuaan alami.

Perawatan electromotor yang terpenting lainnya adalah pada pelimasan, artnya pelumasan pada mesin perlu diperhatikan dengan baik. Kekenatalnya dan sebagainyanya. Fungsi dari pelumas adalah untuk mengurangi gaya gesekan antar komponen sehingga komponen akan lebih awet.

Pompa oli tidak akan bersirkulasi dan tidak akan bekerja jika tidak ada motor penggerak (electromotor), Pelumasan sangat penting untuk menjaga suhu dari mesin, dengan pelumasan yang lebih baik maka komponen mesin yang bergerak diusahakan diharapkan tidak terjadi kerusakan dan mesin dapat beroperasi lebih lama. Sama halnya dengan electromotor, motor penggerak adalah suatu komponen yang mendasar pada mesin-mesin pompa. Jika electromotor tidak bekerja sempurna maka pompa tidak akan bekerja, Tujuan penelitian ini adalah untuk menjelaskan perawatan Komponen oil max pada Mesin Induk untuk mencegah terjadinya kerusakan pada electro motor dan komponen lainnya di KM. Dharma Kartika IX ?

\section{Materi dan Metode}

\section{Motor Pembakaran}

Kapal-kapal yang memakai uap sebagai tenaga penggerak utama dapat kita ketahui, yaitu dimuka nama kapal dinyatakan dengan huruf S.S. (Steam SHIP). Kalau motor diesel sebagai mesin utama, maka biasanya ada huruf-huruf M.S (Motor SHIP) dimuka namanya. Saat ini juga dibuat kapal-kapal dengan penggerak balingbaling dilakukan secara tidak langsung. Mesin utama dapat dipakai mesin motor diesel. Namun poros mesin tidak dihubungkan langsung dengan poros baling-baling, tapi disambungkan dengan poros sebuah dynamo dan atau generator. Dinamomembangkitkan arus listrik yang digunkan untuk menggerakan sebuah motor listrik (electromotor).Pada poros dari motor listrik ini disambungkan dengan propeller. Tergantung dari jenis mesin utamanya, yang berupa motor diesel atau turbin uap, maka untuk sistem ini selalu disebut dengan diesel electric drive atau turbo electric drive.

\section{Electromotor Oil Max Pump (Pompa Oli)}

Pompa[2] oli adalah komponen yang sangat penting dalam sistem pelumasan di kapal. Pompa oli digunakan dalam memberikan tekanan pada oli mesin yang tujuan agar oli dapat bersirkulasi ke seluruh mesin. Pompa oli akan menghisap oli dari Tangki Oli yang sudah terkumpul untuk kemudian dipompa sehingga oli mesin yang ada dijalur sistem pelumasan memiliki tekanan. Tekanan pada oli tersebut akhirnya membuat oli mesin bergerak keseluruh jalur sistem pelumasan dan melumasi bagianbagian mesin. Setelah pelumasan terjadi oli mesin akan jatuh dan tertampung kembali pada bak penampungan oli untuk kemudian disirkulasikan kembali.

Pada mesin banyak komponen yang mengalami gesekan seperti metal, roda gigi, torak, karena gaya gesek yang terjadi karena penghidupan mesin. Karena gaya gesekan ii maka akan terjadi kerusakan pada komponen mesin. Pelumas digunakan untuk mengurangi gaya gesekan pada komponen mesin sehingga lebih awet termasuk pada electromotor.

Perawatan Electromotor Oil Max Pump (Pompa Oli)

Pompa[4] adalah alat yang dipergunakan dengan tujuan memindahkan minyak pelumas sehingga sistem pelumasan.terjadi dengan normal. Pompa ini dioperasikan pada dua tempat, yaitu ruang mesin M/E ( Main Engine ) dan ruang control.

Perawatan yang dilakukan pada elektromotor pump antara lain:

a. Pemeriksaan permukaan gigi-gigi jika terjadi kerusakan, dan kerusakan lainnya.

b. Pemeriksaan gejala kemacetan akibat permukaan kelilingn yang aus, pencegahan dilakukan dengan minyak gemuk ( grease).

c. Pemeriksaan poros jika mungkin terjadi keausan.

d. Pememeriksaa Bantalan dan poros karena kontak pada permukaannya.

e. Jika dipergunkan paking, gantilah pakingnya dengan paking yang baru yang ketebalan dan jenis yang sesuai.

f. Memeriksa permukaan dalam rumah pompa terhadap kemungkinan korosi, keausan dan kerusakan lainnya.

g. Pemeriksaan pada katup katup yang mengatur tekanan minyak pelumas

Metode

Penelitian dilaksanakan di KM. DHARMA KARTIKA IX milik perusahaan PT DHARMA LAUTAN UTAMA dilakuakn tanggal 17 
Januari dengan tanggal 25 Juni 2021.. Tempat penelitian ini adalah dikapal KM. DHARMA KARTIKA IX milik salah satu perusahaan pelayaran di Indonesia. Peralatan yang digunakan dalam penelitian adalah Kunci Shock: Kunci Ring dan Pas:.Vernier Caliper: Avo meter/Ohm meter.

Didalam teknik pengumpulan data penulis menggunakan metode-metode yang sistematis dalam melakukan penelitian. Hal ini dimaksudkan guna memberikan informasi yang lengkap, serta memberikan data-data yang akurat dan bersifat obyektif serta dapat dipertanggung jawabkan. Untuk meneliti permasalahan penyebab kerusakan electromotor oil max pump pada mesin induk diatas kapal KM. DHARMA KARTIKA IX.

Pengumpulan data dilakukan dengan cara observasi, yaitu [5] penelitian yang dilakukan dengan cara peninjauan langsung pada objek yang diteliti. Yaiitu mengamati secara langsung objek dari penyebab terbakarnya electromotor pada pompa oli mesin induk. Studi Pustaka dan wawancara. Wawancara/Interview[6] adalah suatu metode pengumpulan data yang diperlukan dengan cara bertanya langsung kepada orang yang menguasai bidang yang akan diangkat sebagai bahan laporan, dalam hal ini penanya akan dapat mendengar, menyimak dan mencatat secara langsung dari narasumber. Dokumentasi [7] adalah salah satu metode pengumpulan data kualitatif dengan melihat atau menganalisis dokumen-dokumen yang dibuat oleh subjek sendiri atau oleh orang lain.

\section{Hasil dan Pembahasan}

1. Perawatan dan Perbaikan Komponen oil max pump pada Mesin Induk di KM. Dharma Kartika IX.

Perawatan komponen pompa oli yang dilakukan di Kapal KM. Dharma Kartika IX adalah perawatan harian dan perawatan berkala. Perawatan harian dilakukan setiap hari dengan memeriksa semua komponen agar tidak terjadi kerusakan. Dan perawatan berkala bisa dilakukan dengan masa waktu tertentu.

a. Perawatan Harian

Adapun perawatan harian pada komponen oil max pump main engine ini adalah

1) Pemeriksaan Panel Alarm LO max di control room
Setiap jam jam jaga dilakukan pemeriksaan. Perhatikan nyala lampu pada panel di control room jika panel alarm lo max menyala pada saat kapal sandar maka pompa oli I harus diganti ke pompa oli II/cadangan, Hal ini dilakukan supaya panas tidak terjadi. pada electromotor.

2) Pemeriksaan Putaran Electro motor LO pump.

Periksa gerakan putar electromotor oil max pump usahakan selalu setiap jam jaga, electromotor terhindar dari aliran air, atau, tetesan oli serta benda yang bisa menimbulkan putaran terhambat dari electromotor oil pump

3) Pemeriksaan Kebocoran/Tetesan Oli pada komponen Pompa Oli Mesin Induk Kapal KM. Dharma Kartika IX yaitu pemeriksaan komponen yang bisa menimbulkan oli bocor dimungkinkan terjadi pada komponen seperti tempat tangki ekspansi, selang, sambungan pipa, dan lain-sebagainya.

b. Perawatan Berkala

Perawatan berkala dilakukan pada periode tertentu agar komponen kapal dapat terawatt dengan baik yaitu:

1) Perawatan Pompa Minyak Pelumas

a) Pemeriksaan permukaan gigi-gii jika terjadi kerusakan, dan kerusakan lainnya.

b) Pemeriksaan gejala kemacetan akibat permukaan kelilingn yang aus, pencegahan dilakukan dengan minyak gemuk ( grease).

c) Pemeriksaan poros jika mungkin terjadi keausan.

d) Pememeriksaa Bantalan dan poros karena kontak pada permukaannya.

e) Jika dipergunkan paking, gantilah pakingnya dengan paking yang baru yang ketebalan dan jenis yang sesuai

f) Memeriksa permukaan dalam rumah pompa terhadap kemungkinan korosi, keausan dan kerusakan lainnya.

g) Pemeriksaan pada katup katup yang mengatur tekanan minyak pelumas

2) Perawatan Lo Circulation Pump Lo.

a) Pengecekan gigi- giginya pastikan dalam kondisi baik. 
b) Pemeriksaan kebocoran minyak yang diakibatkan oleh packing rusak.

c) Pemeriksaan kenceng tidaknya mur dan baut

3) Perawatan Sump Tank (Tangki Edar)

a) Pemindahan sisa minyak lumas ke tanki Lo Settling Tank.

b) Pembukaan main hole.

c) Pembebasan tanki dari gas beracun melalui metode blower (free gas).

d) Perawatan Lo Store Tank.

Kosongkan tanki minyak lumas dan pemindahan ke tanki yang lain. Pembukaan main hole. Udara segar dimasukan dengan menggunkan blower ke tangki supaya bebas dari gas beracun yang disebebkan penguapan minyak ( Free gas). Perawatan Strainer (Saringan Minyak Pelumas)

Pada umumnya minyak lumas dari mesin mengelurkan panas dan mungkin mengandung kotoran besi atau lainnya. Dan karenanya guna pembersihan minyak pelumas dipergunakan saringan / filter.

Perawatan yang baik akan menghasilkan komponen yang awet [8]-[11] sehingga kan menghasilkan sistem pemerliaraan yang optimal. Pada dasarnya perawatan bertujuan untuk membuat awet komponen dan detetksi dini terhadap kerusakan yang mungkin terjadi. Pada sistem perkapalan perawatan merupakan hal yang wajin sehingg diadakan perawatn harian hingga bulannan dan doking. Pada akhirnya perawatan elektromotot berusaha agar berfungsi secara optimal dan mesin induk tidak terganggu sehingga berjalan normal[12].

2. Perbaikan Electromotor KM.Dharma Kartika IX.

Perbaikan Electromotor di Kapal KM.Dharma Kartika IX adalah dengan mengganti komponen Electromotor yang baru yaitu Rotor baru.

\section{Kesimpulan}

Perawatan komponen Oil max pump di Kapal KM. Dharma Kartika IX adalah perawatan harian dan berkala, perawatan dilakukan dengan mengecek setiap hari komponen Pompa oli dan electro motor supaya temperatur dan kinerja pompa selalu dalam posisi normal, dan perawatan berkala dilakukan dalam jangka waktu satu bulan sampai satu tahun bisa di lihat di $\log$ book atau buku harian mesin. Perawatan sangat diperlukan agar komponen menjadi tahan lama dan awet sehingga akan mengurangi biaya operasional.

\section{Ucapan terima kasih}

Penyelesaian penelitian ini, melibatkan konstribusi dari berbagai pihak. Oleh karena itu penulis mengucapkan terimakasih kepada semua pihak yang terlibat.

\section{Daftar Pustaka}

[1] A. S. Dwiono, A. Hendrawan, and S. Pramono, "Perbaikan Lambung Kapal KM. Harima PT. CSFI-Cilacap," Din. Bahari, vol. 2, no. 1, pp. 56-61, 2021, doi: 10.46484/db.v2i1.261.

[2] Rasyid, "Prinsip Pelumasan," Gramedia Pustaka Utama, 2001.

[3] B. H. Wijaya, "Type Pelumasan Mesin Induk," Jakarta Lib. Pustaka, 2010.

[4] P. S. s Purjiyono, Ningrum Astriawati, "Perawatan Sistem Pelumasan Mesin Utama Pada Kapal Km. Mutiara Sentosa Ii," Teknovasi, vol. 6, pp. 74-80, 2019.

[5] Arikunto, "Metode Penelitian Pengumpulan data," Jakarta PT. Rineka Cipta, p. 2006, 2006.

[6] Mardalis, "Metode Penelitian Suatu data," Jakarta Bumi Aksara, 2003.

[7] H. Herdiansyah, "Metode Penelitian Kualitatif untuk Ilmu-ilmu Sosial. Jakarta: Salemba Humanika," J. Non Form. Educ. Community Empower, vol. 1, no. 1, p. 2010, 2010.

[8] D. Suryani and A. Hendrawan, "STUDI TENTANG SANITASI KAPAL," $J$. Saintara, vol. 4, no. 2, 2020.

[9] A. Hendrawan, L. Lusiani, and R. Aprilian, "Sandblasting pada kapal mv. berlian indah," J. Saintara, vol. 4, no. 2, pp. 26-33, 2020.

[10] A. Hendrawan, "Pengaruh Turbocharger terhadap Daya Mesin Induk KN. Prajapati," Maj. Ilm. Gema Marit., vol. 22, no. 1, pp. 44-48, 2020, doi: 10.37612/gema-maritim.v22i1.50.

[11] A. Hendrawan, "ANALISA PENGEBAB 
KEAUSAN POROS BALING BALING

KAPAL," J. Saintara, vol. 4, no. 1, 2019.

[12] A. Hendrawan, R. Ajun, Siswadi, and Supari, "Penyebab Kerusakan Electro Motor Oil Max Pump pada Mesin Induk di KM . Dharma Kartika IX," J. Saintara, vol. 5 , no. 2 , pp. $28-35,2021$. 